\title{
Building a New Microscopy Center at Miami University
}

\author{
R.E. Edelmann* and M.L. Duley* \\ ${ }^{*}$ Center for Advanced Microscopy \& Imaging, Miami University, Oxford, OH 45056
}

The opportunity to construct a new microscopy laboratory space is a very rare event for those who manage microscopy facilities. As a result, managers have little to no knowledge or skills for such an opportunity if it comes along, and have to get it right the first time or live with our mistakes. Here at Miami University we are just finishing the final days of the relocation of our $2600 \mathrm{ft}^{2}\left(240 \mathrm{M}^{2}\right)$ light and electron microscopy facility to a completely renovated $5300 \mathrm{ft}^{2}(500$ $\mathrm{M}^{2}$ ) microscopy laboratory space. A process that has taken six years to complete. In this paper we are presenting our observations and experiences from this process in the hopes of helping others who may be given a similar opportunity.

The rationale for relocating our microscopy facility were several: (1) We had environmental issues destroying our resolution including building vibration, electromagnetic (EM) fields, acoustical noise from HVAC and fume hoods, and temperature and humidity instability. (2) We had run out of space for replacing older systems with larger more complex microscopes, adding new microscopes, or new sample preparation equipment. (3) Inefficiency of having the facility spread out on two floors of a building and open common lecture areas. For this we were looking at completely renovating space within an existing campus building. Five potential locations were identified and tested over the course of two years. A major part of this extended search was recognizing what makes a good potential site. Natural science and engineering buildings are not good locations, as they contain too much electronic equipment producing too many EM fields and too much acoustical and vibrational noise. Further, they have heavy HVAC and fume hood requirements which add a significant noise background in these buildings. We also found that, for microscopy, older buildings are better than newer buildings. Newer buildings are lighter weight due to improvements in engineering and construction materials, which result in safe lower cost buildings, but they flex and shake and transmit sounds and vibrations well. Older buildings are generally over-built, with massive reinforced concrete and stone construction, and they are solid. Our chosen location was originally built in 1949, and is shared with three museum collections and Anthropology - and is nice and quite.

During planning, design, construction and finally utilization we experienced a number of issues that each offered a unique a learning experience. When faced with determining what makes a good microscope room you are not alone. The EM Vendors have specialists to help plan installations. Our contracted engineering firm, after reading articles on microscopy vibration isolation proposed individual isolation slabs, which were completely redesigned when a specialist firms was consulted. Processed water chillers were piped from one remote location to each scope room. As a "green" initiative the first geothermal loop on campus was installed to provide for condenser cooling for the chillers. The chillers also cool a glass water distillation system. A dedicated cat 6 a network was installed, currently running at 1 gbps but will meet any future needs to at least $40 \mathrm{gpbs}$. A dedicated teaching class room was equipped with projectors, smart board technology and secure network connections for remote operation of microscopes. This class room also has glass door cabinets for microscopy teaching tools and a complete older 
TEM for hands-on exploration of microscope components. As was recommended by a number of folks on the listserv, we were careful to over plan electrical outlets in the facility. We learned not only to focus on the highly specialized microscope rooms but even the hall ways, office spaces, and closets need to be carefully reviewed. Additionally, an electronic lock security server, a web accessible scheduling server, and a dedicated server room were all brought online.

The details of each aspect of this new facility project will be presented to help others as we were helped from earlier renovations that others shared on the microscopy listserv, on the web and in print.
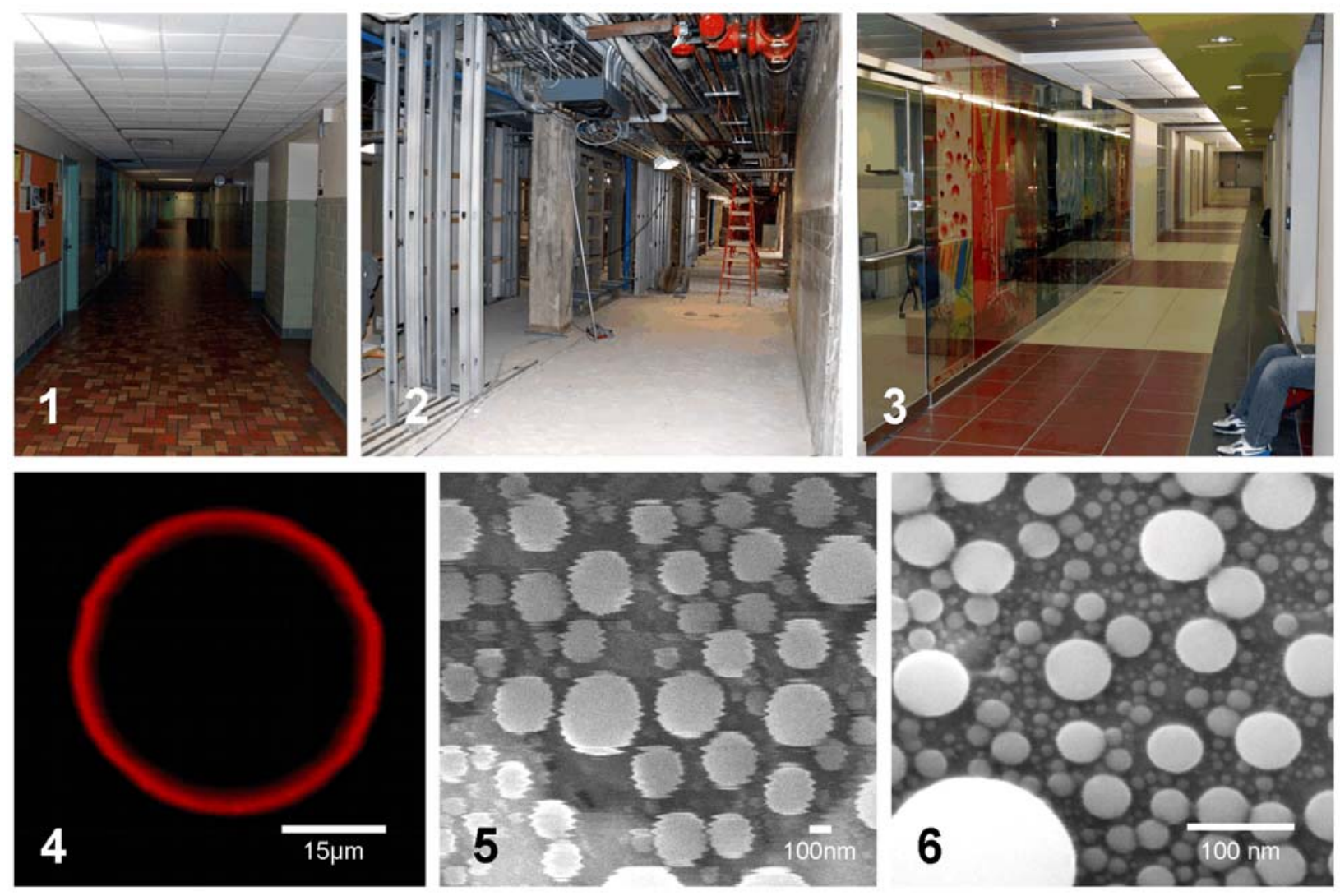

FIGS. 1 - 3. Before, during, and after construction images of the main hallway in the new Microscopy Facility. FIG 4. Confocal test image of $15 \mu \mathrm{m}$ fluorescent bead showing building vibration in old facility. FIG. 5. SEM test image of tin balls in the old facility (imaged at 100,000x). FIG 6. SEM Image of tin balls in the new facility showing improved environmental conditions (imaged at 500,000x). 